\title{
Cause of Construction Material Wastage on Public Building Project in Western Oromia
}

\author{
Garba Wokjira Fayisa ${ }^{1}$, Shiferaw Garoma Wayessa ${ }^{2}$ \\ ${ }^{1}$ Department of Construction Technology and Management, College of Engineering and Technology, Mizan-Tepi University, Tepi, Ethiopia \\ ${ }^{2}$ Departement of Civil Engineering, College of Engineering and Technology, Wollega University, Nekemte, Ethiopia
}

\section{Email address:}

fayisagarba@gmail.com (G. W. Fayisa),yobsan2021@gmail.com (S. G. Wayessa)

\section{To cite this article:}

Garba Wokjira Fayisa, Shiferaw Garoma Wayessa. Cause of Construction Material Wastage on Public Building Project in Western Oromia. American Journal of Civil Engineering. Vol. 9, No. 2, 2021, pp. 55-62. doi: 10.11648/j.ajce.20210902.14

Received: February 13, 2021; Accepted: March 29, 2021; Published: April 26, 2021

\begin{abstract}
In the construction industry, construction material is one of the major cost components and it is $50 \%$ to $70 \%$ of the total construction cost. However, the industry generates 30\%-65\% of wastage for landfill. Effective use of construction material is profitable in the industry as well as in the economy of any country. However, material wastage management in construction are rarely studied by Ethiopian context. Hence, this research is aimed to investigate cause of construction material wastage and rank highly wasted construction material wastage on public building projects in western Oromia. The Study uses both primary and secondary data by structured questionnaires and case study (interviews and site visits). The research has covered a population of General and Building contractors from level one to three and their supervisor's that are employed in western Oromia on public buildings. The purposive sampling techniques were used to collect the data and Analyzed and presented by mean score by using statistical package for social science (SPSS) and excel worksheets. The result of the study analyses, mostly causes of construction materials are; Changes made to the design while construction is in progress, Lack of attention paid to dimensional coordination of products, Damage during transportation, Improper planning for required quantities, Designer's inexperience in method and sequence of construction. In addition, causes of construction material wastages are presented under seven attributes causes. As well as wastage of material on eight key construction, material are ranked as concrete, wooden formwork, block, and steel are most wasted by asking respondents based on their experience in the construction industry. Generally, wastage of material is highly occurred in every activity i.e. during design, construction and during the production of the material.
\end{abstract}

Keywords: Causes of Wastage, Construction Material, Public Building and Wastage

\section{Introduction}

\subsection{Background}

Construction material is one of the major cost components in any construction project. Depending on the types of project cost of materials $50 \%$ to $70 \%$ of the total construction cost $[5,21]$. So that it is important for contractors to consider that, the timely availability of material is the potential cause of successful completion of the project [18]. Researchers study that the construction industry generates up to $30 \%-65 \%$ of total material waste for landfill [11]. In addition, it accounts for the largest portion of global waste up 10-30 present of wastage generated is from the construction industry [10]. At the project level, the waste generated on site estimated to be about $10 \%$ of the materials originally purchased [3]. Many constructors rely that many materials that are wasted on the job site outcome in two cost factors i.e. the material obtaining cost and the waste removal cost [8].

Thus, the sustainability goals and performance of the construction industry where challenged by the huge amount of solid waste. As Mahamid [16] Identified fluctuation in construction, material cost potential cause Contractor's business failure and as one of the major causes of contractor's business failure in developing countries [4, 12]. In addition, in Ethiopia [22]. Identified five factors that cause cost overrun in construction projects from those the second cause is the price of materials. The reduction in construction waste can significantly help in increasing total profit and gaining economic stability for a country and construction firms. 
Since Ethiopia is one of the developing countries those construction industry consumes more economy. A lot of waste occurs during construction, which causes a huge loss to the economy and environment pollution. Similar to other developing countries, Ethiopian construction industry shares many of the problems and challenges that industry is facing in other developing countries. [13, 20]. Therefore, this research gives some importance for the improvement of the performance of contractors and designers regarding the material wastage management as well as for the construction industry.

\subsection{Problem Statement}

In Ethiopia, around the construction project site; there are many wasted of construction materials. This shows that construction materials wastage management has not received attention from researchers and project managers. However, construction materials are costs are increasing from day to day in addition to this waste is becoming a serious problem since it is a high-cost component and effects on the environment, especially on public building construction projects no attention had given to such a subject.
Then, this research determines the current situation with regard to cause of construction material waste in Ethiopia especially in western Oromia. Measure which material is more wasted and issues involved in the generation of waste in the construction industry in western Oromia.

\subsection{Objectives of the Research}

The research is aimed to investigate cause of construction material wastage on public building project in western Oromia and to rank highly wasted material from principal construction material

\section{Methodology}

\subsection{Description of the Study Area}

This Study was conducts in Ethiopian i.e. western Oromia. Ethiopia is located in horn of Africa and she has nine regional states from them this research was conducted in Oromia (Oromiyaa in Afaan Oromo) regional state. Because of the regional state is vast this research was conducted in western parts of Oromia Regional State.

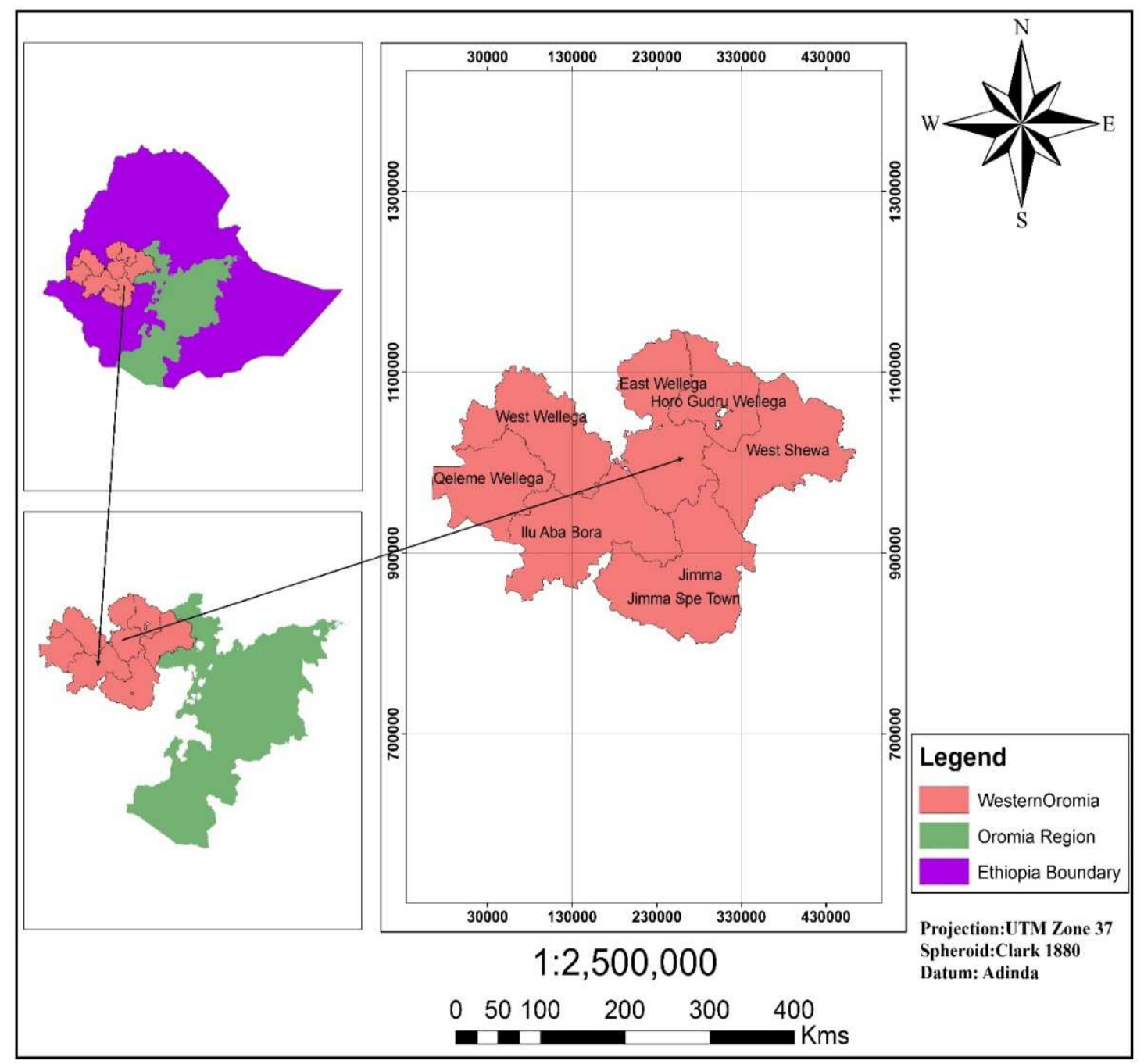

Figure 1. Map of study location. 


\subsection{Sources of Data}

These studies depended on both primary and secondary data. Primary data is made up of first-hand data collected using questionnaires, case studies i.e. interviews and site visits (observation). The questions were created based on the concepts acquired in the literature review. The secondary sources of data obtained using relevant books, journals, magazines, and research papers.

\subsection{Population and Sampling Technique}

The research has coved a population of GC3-GC1 and $\mathrm{BC} 1-\mathrm{BC} 3$ Contractors and their consultants (supervisors) that are employed in western Oromia on public building purposively and it was contact the project manager, office engineer, site engineer, and general Forman as well as the supervisors. The main reason for using this category of construction firms is that they undertake complex and large construction works, in which material wastage is an integral part for them to achieve the main objective of the research.

To determine the minimum sample size that is representative of the population, the KISH FORMULA, which gives a procedure for calculating the minimum sample size will be, applied [14]. Where the populations are grade one to three of building and general contractors registered under construction proxy [2].

The formula works as follows:

$$
n=\mathrm{n}^{1} /\left(1+\mathrm{n}^{1} / \mathrm{N}\right)
$$

Where,

$\boldsymbol{n}=$ Sample size

$\mathrm{N}=$ Total number of population

$\boldsymbol{n}^{1}=\mathrm{S}^{2} / \mathrm{V}^{2}$

$\mathrm{V}=$ the standard error of sampling distribution $=0.05$
$\mathrm{S}^{2}=$ the maximum standard deviation of the population

$\mathrm{P}=$ the proportion of the population elements that belong to the defined region.

Total error $=0.1$ at confidence interval of $95 \%$

$$
\begin{aligned}
\mathrm{S}^{2} & =\mathrm{P}(1-\mathrm{P}) \text { where } \mathrm{P}=0.5 \\
& =0.5(1-0.5) \\
& =0.25
\end{aligned}
$$

$$
\begin{gathered}
\text { Since } \mathrm{n}^{1}=\mathrm{S} 2 / \mathrm{V} 2 \\
=0.25 / 0.0052 \\
\mathrm{n}^{1}=100 \\
\mathrm{~N}=258 \\
\mathrm{~N}=100 /(1+100 / 258) \\
\mathrm{N}=71.8309859 \\
\sim 72
\end{gathered}
$$

\subsection{Method Data Collection and Analysis}

This research uses both survey and case study approaches, which are described below. The questionnaire was composed of two parts with part one-survey questioners and the second part is case study part

To accomplish the aim of the study, as follows:

1. General information of the respondents

2. Causes of construction material waste

3. Most wasted construction material in the site

The questionnaire was prepared in English and it derived from the literature review and measured by Likert scale

Table 1. Questionnaire measurment scale (Likert scale).

\begin{tabular}{llllll}
\hline \multirow{2}{*}{ Questionnaires type } & Scale & \multicolumn{3}{l}{} \\
\cline { 2 - 6 } & $\mathbf{1}$ & $\mathbf{2}$ & $\mathbf{3}$ & $\mathbf{4}$ & \\
\hline Causes material waste & not a waste cause & Insignificant waste cause & neutral & significant waste cause & Major waste cause \\
Highly wasted material & $1 \%-6 \%$ wasted & $7 \%-12 \%$ wasted & $13 \%-18 \%$ wasted & $19 \%-24 \%$ wasted & $25 \%-30 \%$ wasted \\
\hline
\end{tabular}

The case study was conducted by structured interview included close ended and open questions. Interviews held at the construction site for project managers. Direct observation was done by investigating three sites of construction for five working days in the construction site. The observations were carried out by direct visits of construction sites. The researcher spent time at construction sites and observed the flow activities of materials (delivery, transportation, handling, and storage) in addition to observation of conservation activities (rejection of material, labor mistakes, cutting).

Generally questions were constructed: general information about surveyed respondents using tick that fits you, the Binary (e.g., yes/no) and Liker scale. Cause of wastage: not a waste cause, in significant, waste cause, neutral, significant waste cause, Major waste cause. Ranking most wasted construction material: $(1 \%-6 \%)$ wasted, $(7 \%-12 \%)$ wasted, (3\%-18\%) wasted (19\%-24\%) wasted, (25\%-30\%) wasted. In addition, analyzed by using SPSS by mean rank methods.

\section{Results and Discussions}

\subsection{Procedures Results and Discussions}

This chapter result and discusses the survey findings. After the questionnaire survey was collected, statistical analyses were undertaken on the responses using various methods described in the research methodology. Data was analyzed by using SPSS to perform descriptive statistics. The result and discussion of data was done in accordance with the arrangement of objectives of the study. 0 


\subsection{Causes of Construction Materials Waste on Construction Projects}

Respondents have asked to score which factors measured to be major causes of waste in all causes. Generally, by grouping into attributes, all data were pooled together by mean score ranking and presented one by one as the following.

\subsubsection{Design and Documentation Attributes}

The mean score of each sub-causes of the design and documentation attributes which causes materials wastes are presented in table 2. And ranked according to their influence causes as Changes made to the design while construction is in progress, Lack of attention paid to dimensional coordination of products, Designer's inexperience in method and sequence of construction had the highest means score of $4.23,4.14$ and, 3.90 respectively. While the Selection of lowquality products during design, Designer's unfamiliarity with alternative products, incomplete contract documents at commencement of the project had the lowest rank with means $2.91,3.12$, And 3.23 respectively.

Table 2. Design and Documentation Attributes cause's of wastage.

\begin{tabular}{lll}
\hline Design And Documentation Attributes Cause's & MS & Rank \\
\hline Changes made to the design while construction is in progress & 4.230 \\
Lack of attention paid to dimensional coordination of products & 4.1435 \\
Designer's inexperience in method and sequence of construction & 3.8986 \\
Lack of attention standard sizes available on the market during design & 3.8841 & 2 \\
Errors in the contract documents & 3.5797 & 3 \\
Waiting for design documents and drawings & 3.4638 & 4 \\
Lack of information in the drawing & 3.4058 & 6 \\
Complexity of detailing in the drawings & 3.4203 \\
Incomplete contract documents at commencement of the project & 3.2464 \\
Designer's unfamiliarity with alternative products & 3.1159 \\
Selection of low quality products during design & 2.9130 \\
\hline
\end{tabular}

Source: researcher's analysis, 2019

As table 2 indicates that Changes made to the design while construction is in progress is the first ranked wastage causes from design and documentation attributes. A result of an interview with project managers in the case study, sometimes waste occurred because of, designs change while the work is on progress. This cause can explore wastage at two stages: first, if the design changed after the activity had done and if the design had changed after the material supplied. Contractors supply the material to the site of construction but the design was changed. Second, after the activity was performed the design was changed so it needs reconstruction. In addition, case study one shows that wastage was highly caused by design in consideration of wastage form material accessible on the market. The design shows the use of a diameter of 20 reinforcement bar with length $4.4 \mathrm{~m}$ but the length of one bar was $12 \mathrm{~m}$ and one (Beraga) of steel was used at two places the left $3.2 \mathrm{~m}(26.7 \%)$ was wastage and there is wastage of reinforcement like these case.

This result also confirms the result made by Sasitharan Nagapan [19] causative factors of wastage in the construction industry in seven groups with sub-clauses. From design factors, frequent design changes and design errors are the first and second raked cause of wastage in the construction industry and Bekr [7] in Jordan construction site identified: frequent design and client's changes are the first ranked causes of wastage.

\subsubsection{Transportation Attributes}

From five transportation attributes "damage during transportation" is the first ranked cause of material wastage in construction projects with a mean score of 4.10 and inefficient methods of unloading, Insufficient protection during unloading was second and third-ranked with mean score $3.55,3.30$ respectively.

Table 3. Transportation Attributes causes of wastage.

\begin{tabular}{lll}
\hline Transportation Attributes Causes & MS & Rank \\
\hline Damage during transportation & 4.0870 & 1 \\
Inefficient methods of unloading & 3.5507 & 2 \\
Insufficient protection during unloading & 3.3043 & 3 \\
Overloading on transport equipment & 3.2609 & 4 \\
Use of wrong method of transport & 3.1449 & 6 \\
\hline
\end{tabular}

Source: researcher's analysis, 2019

This shows that some most of the construction materials in western Oromia are transported from Finfinnee capital city of Ethiopian, during transportation some material is disused. As a case study (interview and site visit) in appendix two shows, the observation was made on site material like floor finishes, glass and block were broken during transportation since they were supplied from Addis Ababa. In addition, a result of the interview shows wastage has occurred as materials damaged during transportation.

The results confirm earlier findings in the literature which list damage during transportation [7], Damages while transporting [17]

\subsubsection{On-Site Management and Planning Attributes}

As (Table 4) From twelve sub cause attributes of On-Site Management and Planning Attributes Improper planning for required quantities, Lack of supervision, Poor communication coordination between parties involved in the project were the first second and third-ranked construction material wastage cause with mean score value 4.07, 3.78, 3.72 respectively. 
Table 4. On-Site Management and Planning Attributes causes of wastage.

\begin{tabular}{lll}
\hline On-Site Management And Planning Attributes & MS & Rank \\
\hline Improper planning for required quantities & 4.0725 & 1 \\
Lack of supervision & 3.7826 & 2 \\
Poor communication coordination between parties involved in the project & 3.7246 & 3 \\
Slow decision making by the site management & 3.7101 & 4 \\
Lack of technical professionals in contractor's organization & 3.6377 & 5 \\
Waste from application processes (i.e., over-preparation of mortar) & 3.6232 & 6 \\
Lack of quality management system aimed at waste minimization & 3.5942 & 7 \\
Lack of on-site waste management plans & 3.5797 & 8 \\
Lack of on-site material control & 3.5797 & 8 \\
Ineffective control of the project's progress by the constructor & 3.3913 & 9 \\
Poor site layout & 3.3188 & 10 \\
Changing orders/instructions by supervisors & 3.2754 & 11 \\
\hline
\end{tabular}

Source: researcher's analysis, 2019

A case study (interview and site visit), result shows in appendix two observation was made the same amount of concrete was wasted because of formwork prepared for concreting was not enough. In addition, the result of interviews shows waste caused by improper management on site this shows the inefficient planning of pored materials for the required volume of concrete. Observation was made at site improper placement of material at site these causes wastage as well as, The results confirm earlier findings in literature Changing orders/instructions by supervisors, Improper planning, Lack of waste management plan by Muhwezi et al. [15]
Causes of wastes arise from Material Storage Attributes factors on public building construction projects were evaluated by respondents. When the respondents were the professionals (site engineer, project manager, office engineer general, Forman, and supervisors), the results showed all are causes of construction material wastage. Hence, all the data were pooled together as Table 5 below. Improper storing methods, Inappropriate site storage space leading to damage or deterioration, Materials stored far away from point of the application were the first, second and third ranked construction material wastage causes with mean value 3.60 , $3.59,3.52$ respectively.

\subsubsection{Material Storage Attributes}

Table 5. Material Storage Attributes couses of wastage.

\begin{tabular}{lll}
\hline Material Storage Attributes & MS & Rank \\
\hline Improper storing methods & 3.6087 & 1 \\
Inappropriate site storage space leading to damage or deterioration & 3.5942 & 2 \\
Materials stored far away from point of application & 3.5217 & 3 \\
\hline
\end{tabular}

Source: researcher's analysis, 2019

Similarly, as result of case study (interview and site visit shows) observation was made deteriorated steel material around the construction site, improper storage places, improper using material not using "first in first out" principle was observed. The results confirm earlier findings in "Inappropriate storage facilities at the site leading to damage or deterioration, Damages while transporting, Storage, Poor method of storage on site Use of whatever material close to working place" [15].

\subsubsection{Material Handling Attributes}

Respondents were asked to rank causes of Wastes arising from Material Handling Attributes factors on construction projects. The responses were the professionals (site engineer, project manager, office engineer, general Forman, and supervisors) and the result were compared; the results showed all are causes of construction material wastage. Hence, all the data were pooled together (Table 6). From five sub causes of Material Handling Attributes "Using excessive quantities of materials than required, Transportation methods from storage to the point of application, inadequate material handling" were the first, second and third ranked of construction material wastage cause with mean value 3.46 , 3.26 , and 3.17 respectively.

Table 6. Material Handling Attributes causes of wastage.

\begin{tabular}{lll}
\hline Material Handling Attributes Causes & MS & Rank \\
\hline Using excessive quantities of materials than required & 3.4638 & 1 \\
Transportation methods from storage to the point of application & 3.2609 & 2 \\
Inadequate material handling & 3.1739 & 3 \\
Insufficient instructions about handling & 3.0435 & 4 \\
Materials supplied in loose form & 2.6522 & 5 \\
\hline
\end{tabular}

Source: researcher's analysis, 2019 
Similarly in case study (interview and site visit) wastage was occurred during material handling with same material was disused because Left over product from process e.g. concrete, within improper handling like glass, ceramics. Also during site visit the observation was made there is carelessness of labour during handling of material. The above results in Table 6 confirm that in literature which lists [15]

\subsubsection{Site Operation Attributes}

The respondents were rank cause of wastage arise from Site Operation Attributes on construction projects. When the responses of the professionals (site engineer, project manager, office engineer, general Forman, and supervisors), the results showed all are causes of construction material wastage. Hence, all the data were pooled together (Table 7). From 13 sub-attributes of Site Operation Attributes causes of wastage "Unfriendly attitudes of project team and labors, Lack of workers or tradesmen or sub-constructors skills, Errors by tradesmen or operatives" were the first, second and third ranked of construction material wastage with mean value $3.87,3.84,3.78$ respectively.

Table 7. Site Operation Attributes causes of wastage.

\begin{tabular}{lll}
\hline Site Operation Attributes Causes & MS & Rank \\
\hline Unfriendly attitudes of project team and labors & 3.8696 \\
Lack of workers or tradesmen or sub-constructors skills & 3.8406 & 1 \\
Errors by tradesmen or operatives & 3.7826 \\
Conversion of waste from cutting uneconomical shapes & 3.7391 & 2 \\
Rework due to errors by trade persons or laborers & 3.6377 \\
Using untrained/semiskilled manpower & 3.6377 \\
Lack of coordination among different crews & 3.5797 \\
Unfriendly attitudes of workers & 3.5362 \\
Lack of coordination between the main contractor and subcontractor & 3.5217 \\
Choice of wrong construction method & 3.4348 \\
Use of incorrect materials, thus requiring replacement & 3.3768 \\
Poor craftsmanship & 3.3478 \\
Inexperience of construction methods/sequence to be used & 3.3188 \\
\hline
\end{tabular}

Similarly in case study (interview and sit visit) observation was made wastage was made by plasterer with no use of any wastage collection and as interview result shows wastage was occurred on site because of error made on site by site labors and crafts man, as well as by subcontractors cannot give attention for material wastage.

The above results in Table 7 same what confirm that in literature which lists "Rework, Improper worker's skill, Rework due to workers, mistakes, Workmanship Poor" [15, 7, 1]

\subsubsection{Environmental and Others}

Respondents were rank Causes of Wastes arise from
Environmental and Other Attribute factors on public building construction projects. When the responses were the professionals (site engineer, project manager, office engineer, general Forman, and supervisors), the results showed all are causes of construction material wastage. Hence, all the data were pooled together (Table 8). From eight sub-attributes of Environmental and Others Attributes "Difficulties in obtaining work permits, Effect of site conditions, Vandalism or Theft "were the first second and third-ranked of construction material wastage with mean value $3.77,3.72$, 3.64 respectively.

Table 8. Environmental and Others attributes cause.

\begin{tabular}{lll}
\hline Environmental And Others Attributes Cause & MS & Rank \\
\hline Difficulties in obtaining work permits & 3.7681 & 1 \\
Effect of site conditions & 3.7246 & 2 \\
Vandalism or Theft & 3.6377 & 3 \\
Use of unskilled labour & 3.3623 & 4 \\
Effects of subsurface conditions (type of soil, water table) & 3.3478 & 5 \\
Effects of social and political interferences & 3.3333 & 6 \\
Damage by other parties & 3.2174 & 7 \\
Severe weather conditions & 3.1739 & 8 \\
\hline
\end{tabular}

Source: researcher's analysis, 2019

In addition case study (interview and site visit) result shows on site next to design inconsideration theft was waste cause and also in all case study site thy ware said theft as cause of wastage, work permeation keeping also causes. In addition, some days there was wastage because of political effect on construction site. As well as observation was made wasted material was occurred because of rain during casted concrete.
The above results in Table 8 confirm that in literature which lists Effect of weather, Vandalism [19, 15, 7, and 1]

\subsubsection{Summary of causes of construction materials waste}

Questionnaire of this study considered 57 causes of material waste in construction, and those factors were distributed into attributes as mentioned before, namely, OnSite Management and Planning Attributes, Site Operation 
Attributes causes, Design and Documentation Attributes cause's, Material Storage Attributes, Transportation Attributes causes, Environmental and Others attributes cause and Material Handling Attributes causes. Table 9 gives the result of the collected data causes of materials waste and illustrates the mean of the mean ranking of each attribute. The survey revealed that On-Site Management and Planning Attributes, Site Operation Attributes causes, Design, and
Documentation Attributes causes are causes of materials waste with a mean of mean $3.70,3.59$, and 3.57 respectively.

As analysis of the study shows that concrete was highly wasted construction material in study are this shows that concrete are produced at site and this finding: on-site management and planning attributes, site operation attributes causes are the lack of activity at site of project management inefficiency.

Table 9. Mean of mean and ranking of main wastage attributes.

\begin{tabular}{lll}
\hline Summary of causes of wastage attributes & Mean of mean & Rank \\
\hline On-Site Management and Planning Attributes & 3.696 & 1 \\
Site Operation Attributes causes & 3.586 & 2 \\
Design and Documentation Attributes cause's & 3.573 & 3 \\
Material Storage Attributes & 3.571 & 4 \\
Transportation Attributes causes & 3.470 & 5 \\
Environmental and Others attributes cause & 3.446 & 6 \\
Material Handling Attributes causes & 3.119 & 7 \\
\hline
\end{tabular}

Source: researcher's analysis, 2019

\subsection{Rank of Wasted Material in Construction Site}

The respondents were asked which material is highly wasted on your site. When the responses were the professionals (site engineer, project manager, office engineer, general Forman, and supervisors) As shown in table 10 below: Concrete, Timber such as formwork, Blocks, Tiles, Steel (reforested bars), Cement/mortar, Sand, coarse aggregate with rate of wastage 13.30, 12.61, 12.10, 10.43, $10.35,9.48,8.43,8.17$ are wasted respectively

Table 10. Most Wasted Material in Construction Site.

\begin{tabular}{llll}
\hline Materials & MS & MS *6 & Rank \\
\hline Concrete & 2.2174 & 13.3044 & 1 \\
Timber such as formwork & 2.1014 & 12.6084 & 2 \\
Blocks & 2.0145 & 12.087 & 3 \\
Tiles & 1.7391 & 10.4346 & 4 \\
Steel (reforested bars) & 1.7246 & 10.3476 & 5 \\
Cement/mortar & 1.5797 & 9.4782 & 6 \\
Sand & 1.4058 & 8.4348 & 7 \\
coarse aggregate & 1.3623 & 8.1738 & 8 \\
\hline
\end{tabular}

Source: researcher's analysis, 2019

As case study (interview and site visit) shows material wasted at site to site was deferent. in case study one steel reinforcement was highly wasted on case study two wooden formwork was highly wasted and on case study case three cement or mortal was highly wasted. these shows that in addition to best design on site management can affect rate of material wastage. It shows concrete are prepared on site so some materials wasted because of employers are not trained, motivated and as well as no system to detect wastage at site. The result confirms early findings of Eze [9] rank most wasted construction material in Nigerian construction site on 10 construction material as the following; Formworks (from wood/timber), Mortar from rendering/plastering, Sand Crete blockwork \& brickwork, Concrete respectively. However, for these case concrete is highly wasted, from the above argument cause of wastage on site management, site operation and design and documentation factors are the three ranked cause group. And these result confirms, result made by Baytan [6].

\section{Conclusions}

This research discussed the causes of construction material wastage and most wasted material in construction site based on data collected through questionnaires and interview and site visit. Finally, the following conclusions were drawn.

The study indicates that On-Site Management and Planning Attributes, Site Operation Attributes causes, Design and Documentation Attribute factors are the cause of construction material wastage in western Oromia are the three first ranked wastage cause from seven attributes. In addition, Changes made to the design while construction is in progress, Lack of attention paid to dimensional coordination of products, Damage during transportation, Improper planning for required quantities, Designer's inexperience in method and sequence of construction are causes wastage in all attribute groups in high degrees. It shows that lack of management interest and noninvolvement of key 
stakeholders in decision-making and design factors leads to cause wastage of construction

From the study result Concrete, Timber such as formwork and Blocks are the most three wasted materials from eight construction materials.

General construction shareholders are responsible on wastage management because wastage is not the only profit of contractors it also affects the environment and consumes the resource of the country inefficiently, so all stakeholders must headily participate for wastage management and control.

\section{References}

[1] A. A. Dania, J. O. (nd). A Study Of Construction Material Waste Management Practices By Construction Firms In Nigeria. Ahmadu Bello University, Zaria, Kaduna State, Nigeria.

[2] Abinet, D. (2018). https://constructioninethiopia.com/home/. Retrieved from Addis Ababa, Ethiopia.

[3] Adewuyi T.\& Otali M. (2013). Evaluation of causes of construction material waste -case of rivers state. Ethiopian Journal of Environmental Studies and Management, 746-753.

[4] Adnan Enshassi, K. A.-H. (2006). Causes of Contractor's Business Failure in Developing Countries: The Case of Palestine. Journal of Construction in Developing Countries, Vol. 11, No. 2.

[5] Ashwini R. Patil, S. V. (2013). Analyzing Material Management Techniques on. nternational Journal of Engineering and Innovative Technology (IJEIT).

[6] Baytan. (2007). Origins and magnitude of waste in the turkish construction industry. A thesis submitted to the graduate school of natural and applied sciences to Middle East Technical University.

[7] Bekr, G. A. (2014). Study of the Causes and Magnitude of Wastage of Materials on Construction Sites in Jordan. journal of Construction Engineering, Volume 2014, Article ID 283298, 6 pages.

[8] Building (CIB), C. I. (2002). Code of practice for project management for construction and development. Blackwell Publishing 3rd edition.

[9] Eze, E. C. (2017). Assessment of materials waste in the construction industry: A view of Construction Operatives, Tradesmen and Artisans in Nigeria. The International Journal of Engineering and Science (IJES), 6 (4), PP 32-47.
[10] Franco M. and H. (2017). An Investigation of Waste Management Practices in the Zambian Construction Industry. Journal of Building Construction and Planning Research, 5, $1-13$.

[11] J. Solís-Guzmán, J. M.-D.-d.-A. (2009). A Spanish model for quantification and management of wastage management. journal homepage: www.elsevier.com/locate/wasman, 2542 2548.

[12] Jekale W. (2004). Performance for public construction projects in developing countries: Federal road and educational building projects in Ethiopia. Norwegian University of Science \& Technology.

[13] Joro, A. S. (2015). Managing and minimizing wastage of construction materials on selected public building. Addis Ababa: unpuplished msc research.

[14] Kish, L. (1965). Survey Sampling. New York: John Wiley and Sons, Inc.

[15] L. Muhwezi, L. M. Chamuriho and N. M. Lema (2012). An investigation into Materials Wastes on Building Construction Projects in Kampala-Uganda. Scholarly Journal of Engineering Research, 11-18.

[16] Mahamid, I. (2011). Causes of Contractors' Failure: Contractors' View. 2011 2nd International Conference on Construction and Project Management. IPEDR vol. 15. Singapore: IACSIT Press.

[17] Mahesh. D. (2011). A Study on Basic Material Waste in Building Industry: Main Causes and Prevention. National Conference on Recent Trends in Engineering \& Technology.

[18] Rakesh Nayak, R. G. (2016). Management of Construction Materials on Project Site. 4 (2).

[19] Sasitharan Nagapan, I. A. (2012, December 3-4). Issues on Construction Waste: The Need for Sustainable Waste Management. IEEE Colloquium on Humanities, Science \& Engineering Research (CHUSER 2012), 329-334.

[20] Yimam, A. H. (2011). Project Management Maturity In The Construction Industry Of Developing Countries (The Case Of Ethiopian Contractors). University Of Maryland.

[21] Yohannes T, D. P. (2018). Improving Effective Material Management by Identifying common. International Research Journal of Engineering and Technology (IRJET), Volume: 05 (Issue: 01).

[22] Zinabu T.\& Getachew T. (2015). Causes of Contractor Cost Overrun in Construction: The Case of Ethiopian Construction. International Journal of Business and Economics Research, Vol. 4 (No. 4), 180-191. 